\title{
Temporal stability in the genetic structure of Sarcoptes scabiei under the host-taxon law: empirical evidences from wildlife-derived Sarcoptes mite in Asturias, Spain
}

\author{
Samer Alasaad ${ }^{1,2,5^{*}+}$, Álvaro Oleaga ${ }^{3,4 \dagger}$, Rosa Casais ${ }^{4}$, Luca Rossi ${ }^{5}$, Annarita Molinar Min ${ }^{5}$, Ramón C Soriguer ${ }^{2}$ and \\ Christian Gortázar ${ }^{3}$
}

\begin{abstract}
Background: Implicitly, parasite molecular studies assume temporal genetic stability. In this study we tested, for the first time to our knowledge, the extent of changes in genetic diversity and structure of Sarcoptes mite populations from Pyrenean chamois (Rupicapra pyrenaica) in Asturias (Spain), using one multiplex of 9 microsatellite markers and Sarcoptes samples from sympatric Pyrenean chamois, red deer (Cervus elaphus), roe deer (Capreolus capreolus) and red fox (Vulpes vulpes).
\end{abstract}

Results: The analysis of an 11-years interval period found little change in the genetic diversity (allelic diversity, and observed and expected heterozygosity). The temporal stability in the genetic diversity was confirmed by population structure analysis, which was not significantly variable over time. Population structure analysis revealed temporal stability in the genetic diversity of Sarcoptes mite under the host-taxon law (herbivore derived- and carnivore derived-Sarcoptes mite) among the sympatric wild animals from Asturias.

Conclusions: The confirmation of parasite temporal genetic stability is of vital interest to allow generalizations to be made, which have further implications regarding the genetic structure, epidemiology and monitoring protocols of the ubiquitous Sarcoptes mite. This could eventually be applied to other parasite species.

\section{Background}

In the field of parasitology, different molecular markers have been used for parasite genetic characterization and genetic population studies. All molecular studies assume that genetic structure and diversity is relatively stable over time [1,2]. Since allele presence and frequency change over time due to genetic drift, and because of the gene flow between parasite populations from sympatric host species, the assumption of genetic stability may not be accurate [3].

Here we describe, for the first time to our knowledge, a temporal analysis of microsatellite alleles and genetic

\footnotetext{
* Correspondence: samer@ebd.csic.es

+ Contributed equally

'Institute of Evolutionary Biology and Environmental Studies (IEU), University of Zürich, Winterthurerstrasse 190, 8057 Zürich, Switzerland

Full list of author information is available at the end of the article
}

structure at nine polymorphic loci to examine changes in genetic diversity of Sarcoptes mite over time.

Sarcoptes mite continues to affect humans and a wide range of mammalian hosts worldwide [4], while the debate about its specificity by the host is still the subject of ongoing debate [5]. An epidemic can result, just from the introduction of a single case of scabies into crowded living conditions [6], which could entail devastating mortality in wild and domestic animals $[7,8]$. Moreover, recent biochemical and molecular approaches highlighted the threat of emerging acaricide resistance to the treatment of scabies worldwide [9].

Sarcoptes mite infections are endemic in many European wild animals and may cause devastating mortality, which has been reported in the Alpine (Rupicapra rupicapra) and Pyrenean chamois (Rupicapra pyrenaica parva), Iberian ibex (Capra pyrenaica), aoudad (Ammotragus lervia) and red fox (Vulpes vulpes) [10-16]. Notwithstanding, in 
other sympatric hosts only a few cases have ever been reported such as stone marten (Martes foina), badger (Meles meles), lynx (Lynx lynx), roe deer (Capreolus capreolus) and Iberian wolf (Canis lupus) [17-19].

Pyrenean chamois (Rupicapra pyrenaica parva) population in Asturias (Northern Spain) was affected by a sarcoptic mange epizootic, first detected in 1993. Although the origin of the parasitosis could not be demonstrated, infected domestic goats sharing pastures with wild bovids were suspected to be the source of mites, with subsequent evidence of this cross-infection possibility [20,21]. As reported in epidemics affecting other wild ungulate populations [13-15], Sarcoptes scabiei produced an extremely severe effect on chamois population during the first years after eruption [22]. Nowadays the disease can be considered endemic and is still the main health issue affecting Southern chamois.

The number of Sarcoptes generations is influenced by the short generation interval, as well as by the infected host's susceptibility and life expectancy, and hence Sarcoptes mites on an individual host may in fact form an 'infra-population' [23] that has a number of recurrent generations [24]. Sarcoptes population structure is probably that of a species subdivided into genetically small populations with restricted gene flow between local demes [25]. Strong specialisation could be the result of a host taxon-derived shift and, even if two host taxonderived species are sympatric for their host species, they should be considered as allopatric, if the parasites have no possibility of host choice [26].

The aim of the present study was to test the extent of possible changes in the genetic diversity and structure of Sarcoptes mite population from Pyrenean chamois in Asturias within an 11-years interval period (from the epidemic wave in 1997 to the endemic situation in in 2008), and to compare reported molecular data with samples from mangy sympatric red deer, roe deer and red foxes.

\section{Results}

Twenty-nine alleles were detected from the nine microsatellite loci. The allele count for each of the 9 loci ranged from two (Sarms41) to four (Sarms35, Sarms37 and Sarms38). Sixteen private alleles (alleles present in only one population) were detected; all of them were from red fox populations, while no private alleles were detected from the other populations (Table 1). The number of private alleles ranged between one (Sarms34, Sarms36 and Sarms41) and three (Sarms35 and Sarms37).

The missing data from all the used microsatellite loci was 0.0315, ranging between 0 (for Sarms33, Sarms 37, Sarms 38 and Sarms41) and 0.13 (for Sarms36). For all loci examined there was no evidence of LD [linkage disequilibria] ( $\mathrm{P}>0.05)$, and no deviation from HWE [HardyWeinberg equilibrium] was detected from all loci in all the
Table 1 Private alleles detected at the 9 microsatellite loci of the red fox-associated mite population, together with their frequencies

\begin{tabular}{|c|c|c|}
\hline Locus & Allele & Frequency \\
\hline \multirow[t]{2}{*}{ Sarms 33} & 232 & 0.5833 \\
\hline & 240 & 0.4167 \\
\hline Sarms 34 & 174 & 1 \\
\hline \multirow[t]{3}{*}{ Sarms 35} & 148 & 0.7222 \\
\hline & 152 & 0.1111 \\
\hline & 156 & 0.1667 \\
\hline Sarms 36 & 283 & 0.6000 \\
\hline \multirow[t]{3}{*}{ Sarms 37} & 164 & 0.1667 \\
\hline & 170 & 0.5833 \\
\hline & 178 & 0.2500 \\
\hline \multirow[t]{2}{*}{ Sarms 38} & 209 & 0.4167 \\
\hline & 211 & 0.5833 \\
\hline \multirow[t]{2}{*}{ Sarms 40} & 217 & 0.7222 \\
\hline & 243 & 0.2778 \\
\hline Sarms 41 & 234 & 1 \\
\hline \multirow[t]{2}{*}{ Sarms 44} & 270 & 0.3636 \\
\hline & 272 & 0.0909 \\
\hline
\end{tabular}

studied population except Sarms34 and Sarms38 in Pyrenean chamois collected in 1997, and Sarms33, Sarms3538, and Sarms44 in red fox population.

Allele diversity was identical in all loci from both Pyrenean chamois populations from 1997 and 2008, with the exception of Sarms34 and Sarms38: Sarms34 was monomorphic with only 176 bp allele present in Pyrenean chamois from 1997, while Pyrenean chamois from 2008 has two alleles, $176 \mathrm{bp}$ and $198 \mathrm{bp}$. The new allele (198 bp) is present in all the other herbivore sympatric populations (red deer and roe deer), but not in the carnivore-derived Sarcoptes population (red fox). Sarms 38 was monomorphic with only 215 bp allele present in Pyrenean chamois from 1997, while Pyrenean chamois from 2008 has two alleles, $213 \mathrm{bp}$ and $215 \mathrm{bp}$. Again, the new allele (213 bp) is present in all the other herbivore sympatric populations, but not in the carnivore red fox population.

Intra-host variation was detected in six individuals: one Pyrenean chamois from 1997 (variation in Sarms34), three red deer (variation in Sarms34), and two red foxes (variations in Sarms35 and Sarms40).

AMOVA analysis showed differentiation among populations $\left(F_{S T}=0.74808 ; P<0.001\right)$, which indicates that the mite component populations differed greatly. $F_{S T}$ value between both chamois-derived Sarcoptes mite populations was not statically supported $\left(F_{S T}=0.1919\right.$; $p=0.054)$, while red fox-derived Sarcoptes mite population was statistically $(P<0.001)$ different from all other herbivore-derived Sarcoptes mite populations (Table 2). 
Table 2 Matrix of significant $\boldsymbol{F}_{S T} P$ values, with significance level $=\mathbf{0 . 0 5}$ (above diagonal), and population pairwise $\boldsymbol{F}_{S T}$ (below diagonal) for each pairwise comparison of four Sarcoptes mite populations collected in 1997 and 2008 from Asturias, Spain

\begin{tabular}{lccc}
\hline & R. pyrenaica-1997 & R. pyrenaica-2008 & C. elaphus-2008 \\
\hline R. pyrenaica-1997 & - & 0.054 & $<0.001^{*}$ \\
$\frac{\text { R. pyrenaica-2008 }}{\text { C. elaphus-2008 }}$ & 0.1919 & - & 0.099 \\
V. vulpes-2008 & 0.4564 & 0.1179 & - \\
\hline
\end{tabular}

C. capreolus-2008 was not included because of the low sampling size.

These results were confirmed by the average number of pairwise differences between Sarcoptes populations: The lowest differentiation was between the two chamoisderived Sarcoptes populations, and the highest was between red fox-derived Sarcoptes population and the other herbivore-derived Sarcoptes mite populations (Table 3). No pairwise differences were detected within $R$. pyrenaica (1997)-derived Sarcoptes mite population, while the highest value of the average number of pairwise differences was detected within $V$. vulpes-derived Sarcoptes mite population.

The modal value of the statistic $\Delta K$ [27] for the whole dataset showed that the uppermost cluster value was $K$ $=2$ (Figure 1 ). When $\mathrm{K}=2$, all cluster assignments were consistent with the population of origin. Sarcoptes mites from all herbivore hosts were consistently grouped in one cluster, while Sarcoptes mite from red fox (carnivore host) formed another well-supported cluster (Figure 2).

The posterior probability analyses supported our results, since we obtained similar grouping when applying $\mathrm{K}=3,4,5$ and 6 , which demonstrates the complete resolution of populations into distinct clusters (herbivore- and carnivore-derived Sarcoptes mite populations), and illustrates the subpopulations within $R$. pyrenaica2008- and V. vulpes-derived Sarcoptes mite populations (Figure 2).

The scatter plot of the FCA, for individuals (data not shown) and populations (Figure 3) of the microsatellite genotypes using Sarcoptes mite collected from the sympatric wild animals from Asturias, confirmed the results obtained by the Bayesian assignment test. The two chamois-derived Sarcoptes populations were similar and close to the other herbivore-derived populations (red deer and roe deer), and well-differentiated from the carnivore (red fox)-derived Sarcoptes population.

\section{Discussion}

As with other highly divergent taxa, with Sarcoptes scabiei few loci and low sample sizes are sufficient to find strong population differentiation between host species $[28,29]$. The unusually high number of private alleles in red fox population, was the first indicator of the genetic separation and lack of gene flow between Sarcoptes mite from this carnivore animal and the sympatric herbivores (roe deer, red deer and Pyrenean chamois), which is in concordance with the host-taxon effect among Sarcoptes populations from different sympatric wild animals [26].

The few detected cases of infra-host variations could be attributed to the skin-scale phenomenon [24], while the deviation from HWE presented in some loci from the red fox population could be attributed to possible subpopulations within Sarcoptes mites from this host [30,31]. Sarcoptes mites lack free-living stages, and individual hosts, depending on their susceptibility and behaviour, are essentially ephemeral habitats providing patchy environments that hamper random mating [32,33].

Two new alleles were detected in two different loci from the 2008-Pyrenean chamois population comparing with the 1997-population. Both new alleles are present in all the other herbivore sympatric populations, but not in the carnivore red fox population. This could be understood as small change in allele diversity within chamois-derived Sarcoptes population during the 11years interval period, which could be attributed, simply

Table 3 Population average pairwise differences between four Sarcoptes mite derived populations from Asturias, Spain

\begin{tabular}{ccccc}
\hline & R. pyrenaica-1997 & R. pyrenaica-2008 & C. elaphus-2008 & V. vulpes-2008 \\
\hline R. pyrenaica-1997 & 0.00000 & 0.23077 & 0.69231 & 6.91667 \\
$\frac{\text { R. pyrenaica-2008 }}{\text { C.elaphus-2008 }}$ & 0.03385 & 0.39385 & 0.70118 & 6.83974 \\
V. vulpes-2008 & 0.27077 & 0.08272 & 0.84308 & 6.91667 \\
\hline
\end{tabular}

Above diagonal: Average number of pairwise differences between populations (PiXY). Diagonal elements: Average number of pairwise differences within population (PiX). Below diagonal: Corrected average pairwise difference (PiXY-(PiX+PiY)/2). C. capreolus-2008 was not included because of the low sampling size. 


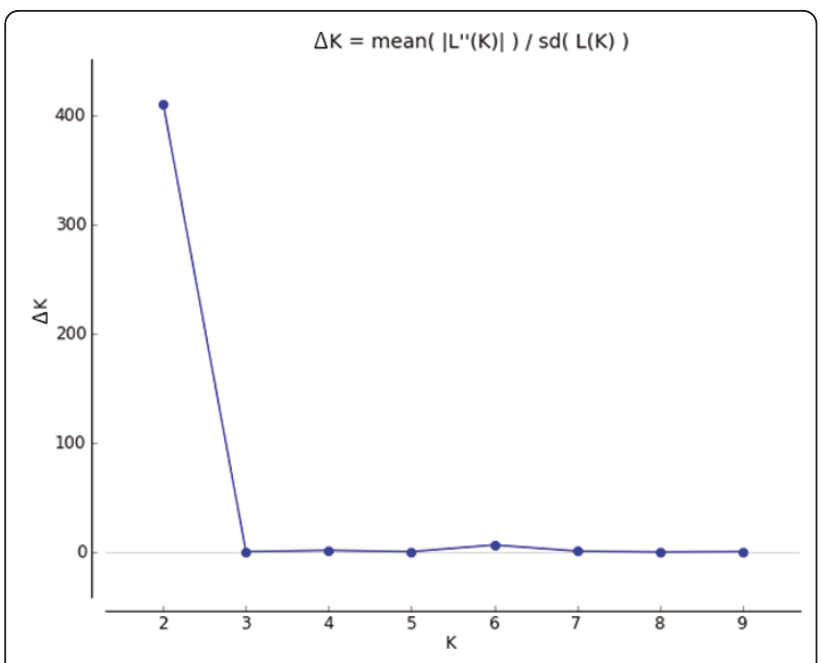

Figure 1 Results of STRUCTURE analysis showing $\Delta \mathrm{K}$ as proposed by Evanno et al. [27]method. The best fit of the data was two clusters.

to non-random sampling, or to little gene flow from the other sympatric herbivore(red deer and roe deer)derived Sarcoptes mite, (since our first 1997-sampling coincided with the start of Sarcoptes outbreak wave in chamois, and it is possible that more waves of Sarcoptes transmission with the other sympatric herbivore hosts have took place until the current endemic situation of Sarcoptes mite in this 2008-chamois population) but never from the carnivore sympatric host (red fox), following the host-taxon law [26].

All AMOVA analysis (showing differentiation among populations), the Bayesian assignment test (between mites), and the scatter plot of the FCA (for individuals and populations) confirmed the absence of genetic differentiation between the two chamois-derived Sarcoptes mite populations collected in 11-year interval period. On the other hand, the results corroborate the presence of a host-taxon phenomenon and lack of gene flow or recent admixture between carnivore- and herbivorederived Sarcoptes populations, among Sarcoptes mites from wild animals in Asturias, in concordance with other European wild hosts [26].

Mite transmission may occur within each host taxonderived Sarcoptes mite population (explaining temporal and geographical coincidences reported between chamois and red deer sarcoptic mange cases in the studied area and confirming their suspected common origin; [34]), but it seems to be extremely rare or absent between them [26].

\section{Conclusions}

The analysis of 11-year interval period found little change in the genetic diversity and showed clear temporal stability in the genetic structure of Sarcoptes mite population under the host-taxon law. The understanding of this factor is crucial, if generalizations are to be made concerning temporal genetic stability. Besides the genetic implications of our results, this study could have further ramification in the epidemiological studies and the monitoring protocols of the neglected Sarcoptes mite, and could have further applications in other parasite species.

\section{Methods}

\section{Specimen collection and DNA extraction}

Using postponed isolation and direct isolation (with aqueous potassium hydroxide digestion) techniques [35] sixty representative adult mites were collected during two different periods, 1997 and 2008: (i) in 1997, twenty Sarcoptes mite were collected from the skin crust of ten infected Pyrenean chamois, and (ii) in 2008, fourteen parasites were collected from the skin crust of seven infected Pyrenean chamois, two mites from two mangy roe deer, thirteen from eight infected red deer, and twelve from six red fox.

All mites were identified as S. scabiei on the basis of known morphological criteria [36]. The DNA of individual Sarcoptes mites was extracted using the HotSHOT Plus ThermalSHOCK technique [37], as following: $25 \mu \mathrm{l}$ of an alkaline lysis reagent $(25 \mathrm{mM} \mathrm{NaOH}, 0.2 \mathrm{mM}$ disodium EDTA; $\mathrm{pH}=12$ ) was used as a substrate for individual Sarcoptes mite DNA extraction by three cycles of thermal shock $\left(2 \mathrm{~min}\right.$ at $-80^{\circ} \mathrm{C}$, freezing step, and $15 \mathrm{~s}$ at $+70^{\circ} \mathrm{C}$, thawing step), followed by a short incubation $\left(30 \mathrm{~min}\right.$ at $95^{\circ} \mathrm{C}$ ) and $\mathrm{pH}$ adjustment with 25 $\mu \mathrm{l}$ of a neutralizing reagent $(40 \mathrm{mM}$ Tris- $\mathrm{HCl} ; \mathrm{pH}=5)$. Two blanks (reagents only) were included in each extraction to monitor for contamination.

\section{Fluorescent-based polymerase chain reaction analysis of microsatellite DNA}

As described by Alasaad et al. [24], nine specific Sarcoptes mite microsatellites (Sarms 33-38, 40, 41 and 44) were used with one $9 \times$ multiplex PCR. One primer from each set was 5' labelled with 6-FAM, VIC, NED or $\mathrm{PET}^{\circledR}$ fluorescent dye tag (Applied Biosystems, Foster City, CA, USA). Each $15 \mu \mathrm{l}$ PCR reaction mixture consisted of $3 \mu \mathrm{l}$ of the single mite DNA, together with the PCR mixture containing all primer pairs (ranged from 0.04 to $0.1 \mu \mathrm{M}$ per primer), $200 \mu \mathrm{M}$ of each $\mathrm{dNTP}, 1.5$ $\mu \mathrm{l}$ of $10 \times$ PCR buffer $(200 \mathrm{mM} \mathrm{KCl}$ and $100 \mathrm{mM}$ Tris$\mathrm{HCl}, \mathrm{pH} 8.0), 1.5 \mathrm{mM} \mathrm{MgCl} 2$ and $0.15 \mu \mathrm{l}(0.5 \mathrm{U} / \mathrm{reac}-$ tion) HotStar Taq (QIAGEN, Milano, Italy). The thermal profile in a 2720 thermal cycler (Applied Biosystems, Foster City, CA, USA) was as following: 15 min at $95^{\circ} \mathrm{C}$ (initial denaturing), followed by 37 cycles of three steps of $30 \mathrm{~s}$ at $94^{\circ} \mathrm{C}$ (denaturation), $45 \mathrm{~s}$ at $55^{\circ} \mathrm{C}$ (annealing) and $1.5 \mathrm{~min}$ at $72^{\circ} \mathrm{C}$ (extension), before a 


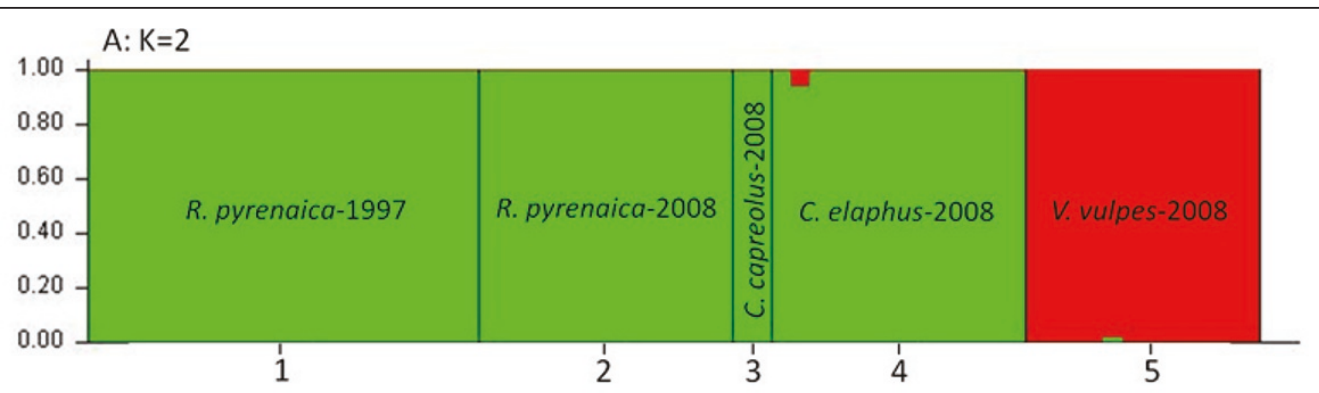

$B: K=3$

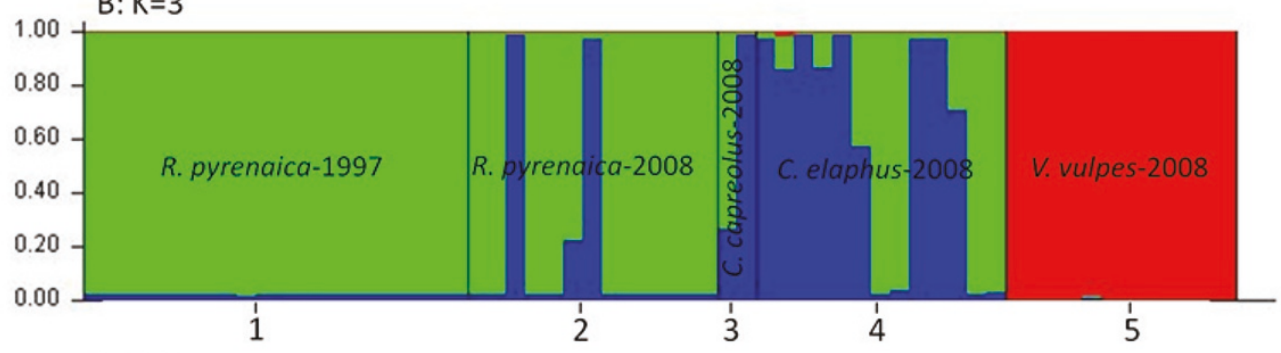

C: $K=4$

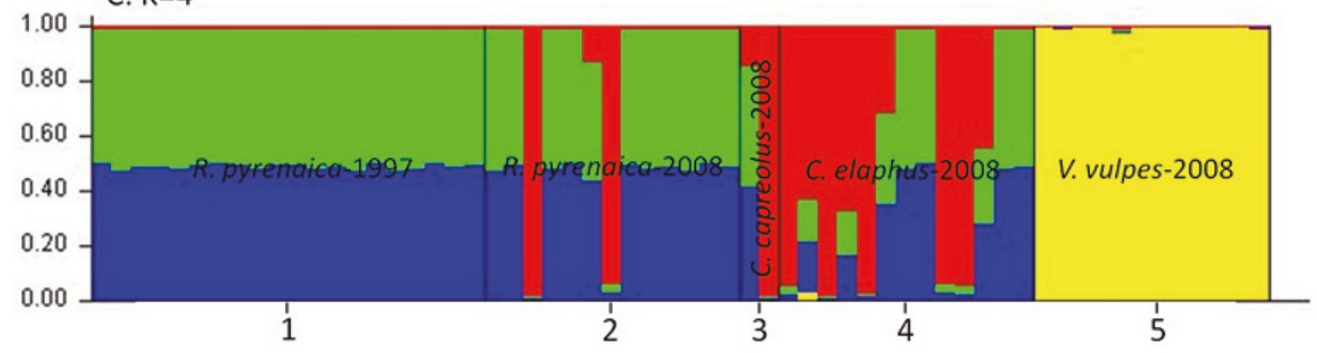

$D: K=5$

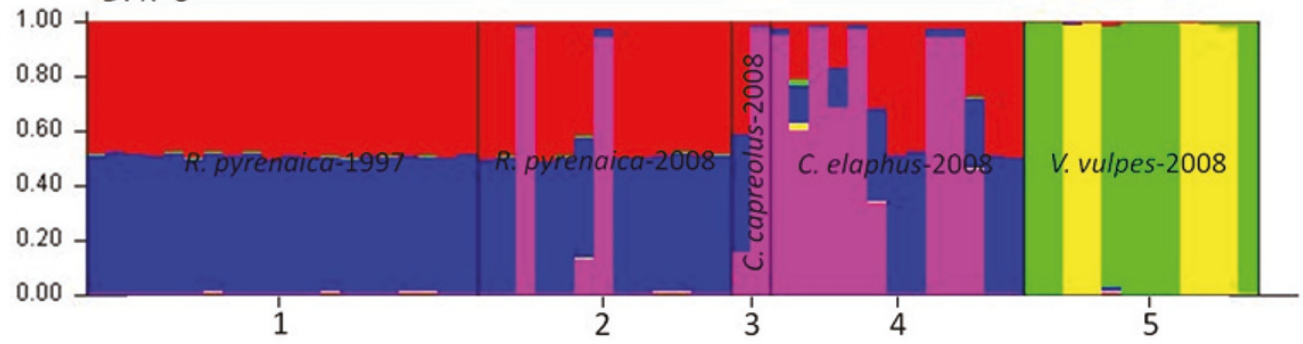

$E: K=6$

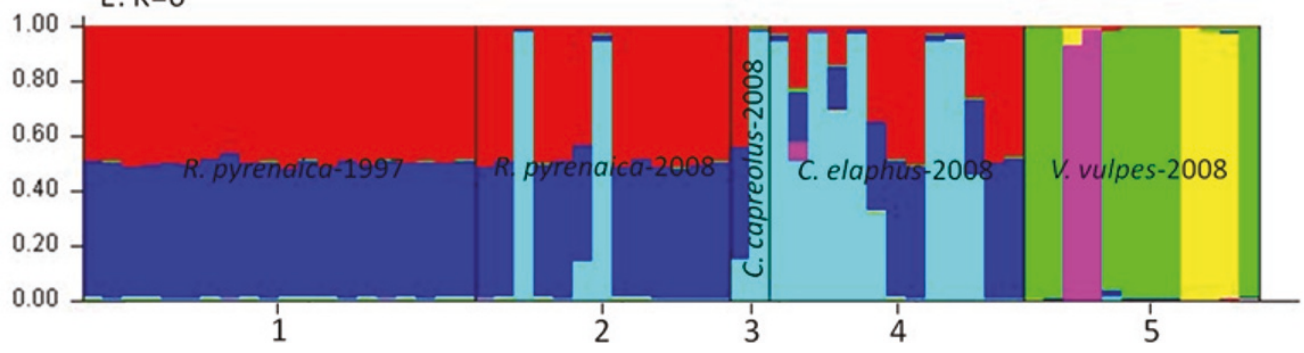

Figure 2 Bar plotting of the proportion of individual variation of 60 Sarcoptes mite from different host species in Asturias (Spain) collected with 11-years interval, assigned to a given genetic clusters in STRUCTURE, when two $(A: K=2)$, three (B: $K=3$ ), four (C: $K=$ 4), five ( $\mathrm{D}: \mathrm{K}=5)$, and six $(\mathrm{E}: \mathrm{K}=6)$ populations are assumed in the dataset. Each cluster is represented by a different colour. 1: $R$. pyrenaica-1997. 2: R. pyrenaica-2008. 3. C. capreolus-2008. 4: C. elaphus-2008. 5: V. vulpes-2008. 


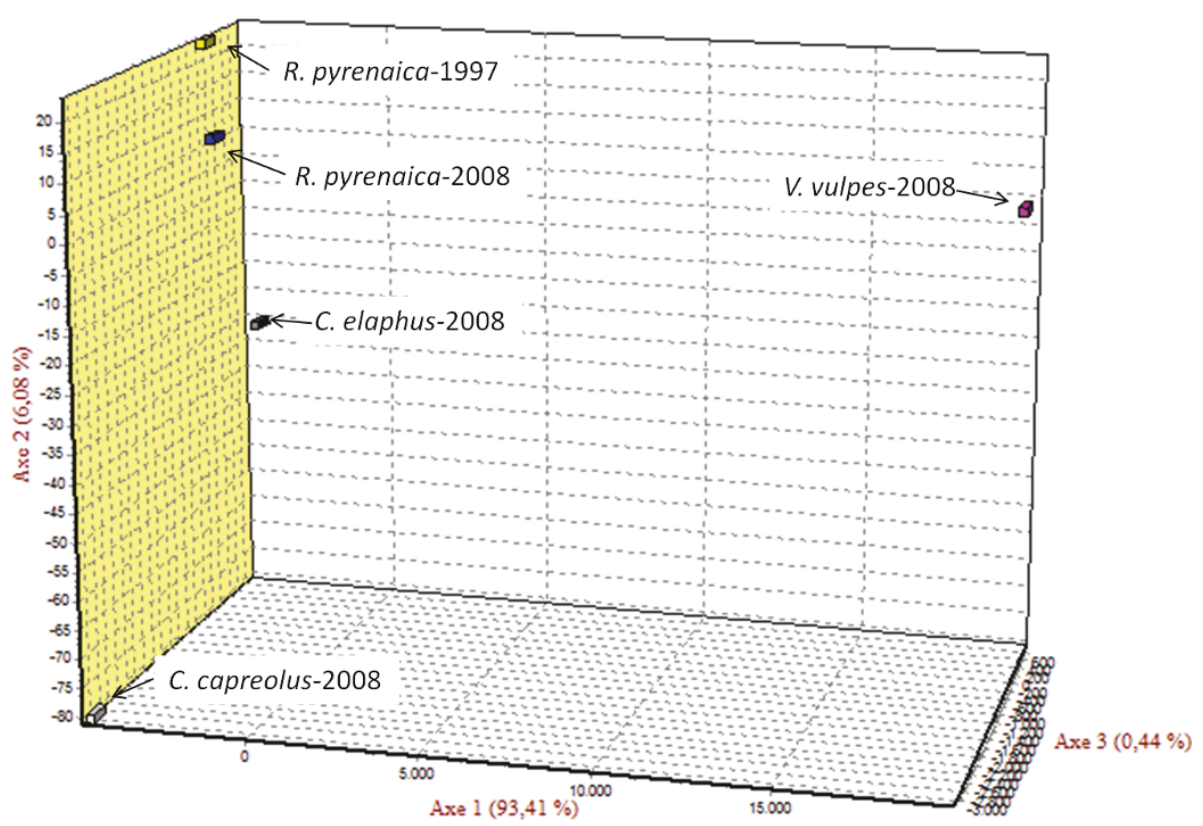

Figure 3 Factorial Component Analysis (FCA) of the proportion of variation of five Sarcoptes mite populations from Asturias (Spain) assigned to a given genetic clusters in Genetix.

final elongation of $7 \mathrm{~min}$ at $72^{\circ} \mathrm{C}$. Fluorescent PCR amplification products were analyzed using formamide with Size Standard 500 Liz (Applied Biosystems, Foster City, CA, USA) by ABI PRISM 310 Genetic Analyzer with pop4. Allele calling was performed using the GeneMapper v. 4.0 software (Applied Biosystems, Foster City, CA, USA).

\section{Molecular analyses}

Expected $\left(H_{E}\right)$ and observed $\left(H_{O}\right)$ heterozygosity, linkage disequilibria (LD), and Hardy-Weinberg equilibrium (HWE) tests were calculated using GENEPOP (v.3.4; [38]). Deviations from HWE and tests for LD were evaluated using Fisher's exact tests and sequential Bonferroni corrections. We estimated genetic diversity using three values; mean number of alleles, expected, and observed heterozygosity based on data from all nine loci. Possible genotyping mistakes (scoring error due to stuttering, large allele dropout) were estimated using MICROCHECKER [39].

The heterogeneity of genetic diversity among the different Sarcoptes mite populations was estimated by the partition of variance components (AMOVA) applying conventional $F_{S T}$ statistics using allele frequencies as implemented in Arlequin 3.11 [40]. The analysis of relationships between mites was carried out by the Bayesian assignment test of the software STRUCTURE (v.2.3.3; [41]). Burn-in and run lengths of Markov chains were both 100000 . We ran 30 independent runs for each $\mathrm{K}$ (for $\mathrm{K}=1-10$ ). The most likely number of clusters was determined using the method of Evanno et al. [27]. Finally, each of the inferred clusters was associated with the component populations of its mites.

The degree of genetic relationship among populations was further investigated with FCA (Factorial Component Analysis) as implemented in Genetix v.4.05.2 [42].

\section{Acknowledgements}

We would like to thank S. Maione, R. Rasero and D. Soglia (Università degli Studi di Torino, Italy) for offering laboratory infrastructure. Thanks are also due to Jaime Marcos Beltrán, Francisco Alonso Mier (Gobierno del Principado de Asturias), Óscar Rodríguez, María Suárez (IREC) and Alberto Espí (SERIDA) for their assistance in field, necropsy and laboratory work. The experiments comply with the current laws of the countries in which the experiments were performed. The research was supported by a RTA 200900114-00-00 (INIA) project, RNM-6400, Proyecto de Excelencia (Junta de Andalucia, Spain) and Juan de la Cierva grant. This work is a contribution to the agreement between IREC - CSIC and Principado de Asturias.

\section{Author details}

${ }^{1}$ Institute of Evolutionary Biology and Environmental Studies (IEU), University of Zürich, Winterthurerstrasse 190, 8057 Zürich, Switzerland. Estación Biológica de Doñana, Consejo Superior de Investigaciones Científicas (CSIC), Avda. Américo Vespucio s/n 41092 Sevilla, Spain. Instituto de Investigación en Recursos Cinegéticos IREC (CSIC-UCLM-JCCM). Ronda de Toledo, s/n, 13071, Ciudad Real, Spain. ${ }^{4}$ SERIDA, Servicio Regional de Investigación y Desarrollo Agroalimentario, Centro de Biotecnología Animal, 33394 DevaGijón, Asturias, Spain. ${ }^{5}$ Dipartimento di Produzioni Animali, Epidemiologia ed Ecologia, Università degli Studi di Torino, Via Leonardo da Vinci 44, I-10095, Grugliasco, Italy.

\section{Authors' contributions}

$C G, R C, A O, L R$ and $R C S$ conceived and designed the experiments. $A O, R C$ and $C G$ performed the field work experiments. AMM, AO and SA performed the molecular work. Manuscript was written by all co-authors. All authors read and approved the final manuscript. 
Competing interests

The authors declare that they have no competing interests.

Received: 1 July 2011 Accepted: 27 July 2011 Published: 27 July 2011

\section{References}

1. Garant D, Dodson JJ, Bernatchez L: Ecological determinants and temporal stability of the within-river population structure in Atlantic salmon (Salmo salar L.). Mol Ecol 2000, 9:615-628.

2. Heath DD, Busch C, Kelly J, Atagi DY: Temporal change in genetic structure and effective population size in steelhead trout (Oncorhynchus mykiss). Mol Ecol 2002, 11:197-214.

3. Lessios HA, Weinberg JR, Starczak VR: Temporal variation in populations of the marine isopod Excirolana: how stable are gene frequencies and morphology? Evolution 1994, 48:549-563.

4. Alasaad S, Walton S, Rossi L, Bornstein S, Abu-Madi M, Soriguer RC, Fitzgerald S, Zhu XQ, Zimmermann W, Ugbomoiko US, Pei KJC, Heukelbach J: Sarcoptes-World Molecular Network (Sarcoptes-WMN): integrating research on scabies. Int J Infect Dis 2011, 15:294-297.

5. Walton SF, Holt DC, Currie BJ, Kemp DJ: Scabies: New future for a neglected disease. Adv Parasitol 2004, 57:309-376.

6. Obasanjo OO, Wu P, Conlon M, Karanfil LV, Pryor P, Moler G, Anhalt G, Chaisson Perl TM: An outbreak of scabies in a teaching hospital: lessons learned. Infect Control Hosp Epidemiol 2001, 22:13-18.

7. Heukelbach J, Feldmeier H: Scabies. Lancet 2006, 367:1767-1774

8. Soulsbury CD, lossa G, Baker PJ, Cole NC, Funk SM, Harris S: The impact of sarcoptic mange Sarcoptes scabiei on the British fox Vulpes vulpes population. Mammal Rev 2007, 37:278-296.

9. Mounsey KE, Pasay CJ, Arlian LG, Morgan MS, Holt DC, Currie BJ, Walton SF, McCarthy JS: Increased transcription of Glutathione S-transferases in acaricide exposed scabies mites. Parasit Vectors 2010, 3:43.

10. Fandos P: La cabra montés (Capra pyrenaica) en el Parque Natural de Las Sierras de Cazorla, Segura y Las Villas. ICONA-CSIC Madrid 1991.

11. Mörner T: Sarcoptic mange in Swedish wildlife. Revue Scientifique et Technique de l'Office International des Epizooties 1992, 11:115-121.

12. Pérez JM, Ruíz-Martínez I, Granados JE, Soriguer RC, Paulino F: The dynamics of sarcoptic mange in the ibex population of Sierra Nevada in Spain - influence of climatic factors. J Wild Res 1997, 2:86-89.

13. León-Vizcaíno L, Ruíz de Ybáñez MR, Cubero MJ: Sarcoptic mange in Spanish ibex from Spain. J Wild Dis 1999, 35:647-659.

14. González-Candela M, León-Vizcaino L, Cubero-Pablo MJ: Population effects of sarcoptic mange in Barbary sheep (Ammotragus lervia) from Sierra Espuña Regional Park, Spain. J Wildl Dis 2004, 40:456-465.

15. Rossi L, Fraquelli C, Vesco U, Permunian R, Sommavilla GM, Carmignola G, Da Pozzo M, Meneguz PG: Descriptive epidemiology of a scabies epidemic in chamois in the Dolomite Alps, Italy. Eur J Wildl Res 2007, 53:131-141.

16. Alasaad S, Soglia D, Spalenza V, Maione S, Soriguer RC, Pérez JM, Rasero R, Ryser Degiorgis MP, Nimmervoll H, Zhu XQ, Rossi L: Is ITS-2 rDNA suitable marker for genetic characterization of Sarcoptes mites from different wild animals in different geographic areas? Vet Parasitol 2009, 159:181-185

17. Ryser-Degiorgis MP, Ryser A, Bacciarini LN, Angst C, Gottstein B, Janovsky M, Breitenmoser U: Notoedric and sarcoptic mange in free-ranging lynx from Switzerland. J Wildl Dis 2002, 38:228-232

18. Oleaga A, Balseiro A, Gortázar C: Sarcoptic mange in two roe deer (Capreolus capreolus) from northern Spain. Eur J Wildl Res 2008, 54:134-137.

19. Oleaga A, Casais R, Balseiro A, Espí A, Llaneza L, Hartasánchez A, Gortázar C: New techniques for an old disease: sarcoptic mange in the lberian wolf. Vet Parasitol 2011.

20. Lavín S, Ruiz-Bascaran M, Marco I, Fondevila MD, Ramis AJ: Experimental infection of chamois (Rupicapra pyrenaica parva) with Sarcoptes scabiei derived from naturally infected goats. J Vet Med 2000, 47:693-699.

21. Menzano A, Rambozzi L, Rossi L: A severe episode of wildlife derived scabies in domestic goats in Italy. Small Rum Res 2007, 70:154-158.

22. Fernández-Moran J, Ballesteros F, Quirós P, Benito JJ, Feliu C, Nieto JM: Epizootiology of sarcoptic mange in a population of cantabrian chamois (Rupicapra pyrenaica parva) in Northwestern Spain. Vet Parasitol 1997, 73:163-171.
23. Bush AO, Lafferty KD, Lotz JM, Shostak AW: Parasitology meets ecology on its own terms: Margolis et al. revisited. J Parasitol 1997, 83:575-583.

24. Alasaad S, Soglia D, Sarasa M, Soriguer RC, Pérez JM, Granados JE, Rasero R, Zhu XQ, Rossi L: Skin-scale genetic structure of Sarcoptes scabiei populations from individual hosts: empirical evidence from Iberian ibexderived mites. Parasitol Res 2008, 104:101-105.

25. Martínez JG, Soler JJ, Soler M, Møller AP, Burke T: Comparative population structure and gene flow of a brood parasite, the great spotted cuckoo (Clamator glandarius) and its primary host, the magpie (Pica pica). Evolution 1999, 53:269-278.

26. Rasero R, Rossi L, Maione S, Sacchi P, Rambozzi L, Sartore S, Soriquer R, Spalenza V, Alasaad S: Host taxon-derived Sarcoptes mites in European wildlife animals, revealed by microsatellite markers. Biological Conservation 2010, 143:1269-1277.

27. Evanno G, Regnaut S, Goudet J: Detecting the number of clusters of individuals using the software STRUCTURE: a simulation study. Mol Ecol 2005, 14:2611-2620.

28. Walton SF, Dougall A, Pizzutto S, Holt D, Taplin D, Arlian LG, Morgan M, Currie BJ, Kemp DJ: Genetic epidemiology of Sarcoptes scabiei (Acari: Sarcoptidae) in northern Australia. Int J Parasitol 2004, 34:839-849.

29. Tadano R, Nishibori M, Tsudzuki M: High accuracy of genetic discrimination among chicken lines obtained through an individual assignment test. Anim Genet 2008, 39:567-571.

30. Hardy GH: Mendelian proportions in a mixed population. Science 1908 28:49-50.

31. Stern C: The Hardy-Weinberg law. Science 1943, 97:137-138.

32. Price PW: Evolutionary biology of parasites. Princeton University Press, Princeton NJ; 1980

33. Criscione CD, Poulin R, Blouin S: Molecular ecology of parasites: elucidating ecological and microevolutionary processes. Mol Ecol 2005, 14:2247-2257.

34. Oleaga A, Casais R, González-Quirós P, Prieto M, Gortázar C: Sarcoptic mange in red deer from Spain: improved surveillance or disease emergence? Vet Parasitol 2008, 154:103-113.

35. Alasaad S, Rossi L, Soriguer RC, Rambozzi L, Soglia D, Pérez JM, Zhu XQ: Sarcoptes mite from collection to DNA extraction: the lost realm of the neglected parasite. Parasitol Res 2009, 104:723-732.

36. Fain A: Étude de la variabilité de Sarcoptes scabiei avec une revisiondes Sarcoptidae. Acta zoologica et pathologica Antverpiensia 1968, 47:1-196.

37. Alasaad S, Rossi L, Maione S, Sartore S, Soriguer RC, Pérez JM, Rasero R, Zhu XQ, Soglia D: HotSHOT Plus ThermalSHOCK, a new and efficient technique for preparation of PCR-quality Sarcoptes mite genomic DNA. Parasitol Res 2008, 103:1455-1457.

38. Raymond M, Rousset F: GENEPOP version 1.2: a population genetics software for exact test and ecumenicism. J Hered 1995, 86:248-249.

39. Oosterhout C, Hutchinson WF, Wills DPM, Shipley P: MICRO-CHECKER: software for identifying and correcting genotyping errors in microsatellite data. Mol Ecol Notes 2004, 4:535-538.

40. Excoffier L: Arlequin 3.11 copyright 2006. CMPG University of Berne; 2006 [http://cmpg.unibe.ch/software/arlequin3].

41. Pritchard JK, Stephens M, Donnelly P: Inference of population structure using multilocus genotype data. Genetics 2000, 155:945-959.

42. Belkhir K: GENETIX, logiciel sous WindowsTM pour la génétique des populations, Laboratoire Génome et Populations, Université de Montpellier II. 1999 [http://www.genetix.univ-montp2.fr/genetix/genetix. $\mathrm{htm}$.

doi:10.1186/1756-3305-4-151

Cite this article as: Alasaad et al:: Temporal stability in the genetic structure of Sarcoptes scabiei under the host-taxon law: empirical evidences from wildlife-derived Sarcoptes mite in Asturias, Spain. Parasites \& Vectors 2011 4:151 